\title{
Are neonicotinoid insecticides driving declines of widespread butterflies?
}

Andre S Gilburn, Nils Bunnefeld, John McVean Wilson, Marc S Botham, Tom M Brereton, Richard Fox, Dave Goulson

There has been widespread concern that neonicotinoid pesticides may be adversely impacting wild and managed bees for some years, but recently attention has shifted to examining broader effects they may be having on biodiversity. For example in the Netherlands, declines in insectivorous birds are positively associated with levels of neonicotinoid pollution in surface water. In England, the total abundance of widespread butterfly species declined by $58 \%$ on farmed land between 2000 and 2009 despite both a doubling in conservation spending in the UK, and predictions that climate change should benefit most species. Here we build models of the UK population indices from 1985 to 2012 for 17 widespread butterfly species that commonly occur at farmland sites. Of the factors we tested, three correlated significantly with butterfly populations. Summer temperature and the index for a species the previous year are both positively associated with butterfly indices. By contrast, the number of hectares of farmland where neonicotinoid pesticides are used is negatively associated with butterfly indices. Indices for 15 of the 17 species show negative associations with neonicotinoid usage. The declines in butterflies have largely occurred in England, where neonicotinoid usage is at its highest. In Scotland, where neonicotinoid usage is comparatively low, butterfly numbers are stable. Further research is needed urgently to show whether there is a causal link between neonicotinoid usage and the decline of widespread butterflies or whether it simply represents a proxy for other environmental factors associated with intensive agriculture. 
2

3

Are neonicotinoid insecticides driving declines of widespread butterflies?

\author{
Andre S. Gilburn'1, Nils Bunnefeld ${ }^{1}$, John Wilson', Marc S. Botham ${ }^{2}$, Tom Brereton ${ }^{3}$, \\ Richard Fox ${ }^{3}$, Dave Goulson ${ }^{4}$ \\ ${ }^{1}$ School of Natural Sciences, University of Stirling, Stirling FK9 4LA, UK \\ ${ }^{2}$ Centre for Ecology and Hydrology, Crowmarsh Gifford, OX10 8BB, UK \\ ${ }^{3}$ Butterfly Conservation, Manor Yard, East Lulworth, Wareham, Dorset, BH20 5QP, UK \\ ${ }^{4}$ School of Life Sciences, University of Sussex, BN1 9QG, UK
}

\title{
Abstract
}

There has been widespread concern that neonicotinoid pesticides may be adversely impacting wild and managed bees for some years, but recently attention has shifted to examining broader effects they may be having on biodiversity. For example in the Netherlands, declines in insectivorous birds are positively associated with levels of neonicotinoid pollution in surface water. In England, the total abundance of widespread butterfly species declined by $58 \%$ on farmed land between 2000 and 2009 despite both a doubling in conservation spending in the UK, and predictions that climate change should benefit most species. Here we build models of the UK population indices from 1985 to 2012 for 17 widespread butterfly species that commonly occur at farmland sites. Of the factors we tested, three correlated significantly with butterfly populations. Summer temperature and the index for a species the previous year are both positively associated with butterfly indices. By contrast, the number of hectares of farmland where neonicotinoid pesticides are used is negatively associated with butterfly indices. Indices for 15 of the 17 species show negative associations with neonicotinoid usage. The declines in butterflies have largely occurred in England, where neonicotinoid usage is at its highest. In Scotland, where neonicotinoid usage is comparatively low, butterfly numbers are stable. Further research is needed urgently to show whether there is a causal link between neonicotinoid usage 
31 and the decline of widespread butterflies or whether it simply represents a proxy for other

32 environmental factors associated with intensive agriculture.

34 Introduction

In England, the overall population level of widespread butterflies on monitored farmland sites declined by 58\% between 2000 and 2009 (Brereton et al., 2011). This has occurred despite conservation spending in the UK more than doubling in real terms over the same period (JNCC 2015), with some of this spend funding agri-environment schemes that ought to benefit farmland biodiversity (Batáry et al., 2015). Additionally, models predict that moderate climate change should actually benefit most UK butterflies through warmer summer temperatures (Roy et al., 2001, Warren et al., 2001). Although habitat deterioration resulting from land-use change (e.g. agricultural intensification) is likely to be the most important factor driving long-term declines of UK butterflies (Warren et al., 2001) and weather the principle factor determining inter-annual fluctuations (Brereton et al., 2011), the precise reasons for the recent decline are undetermined. While the negative impact of modern, intensive agriculture on biodiversity has been widely recognised (Donald et al., 2001, Kleijn et al., 2009), the relative contribution that agricultural pesticides make to this overall impact has rarely been examined (Gibbs et al., 2009), and never, to our knowledge, on population-level trends in butterflies. A recent review assessing the impacts of pesticides on non-target species has identified a clear need for studies investigating the effects of pesticides on Lepidoptera that inhabit farmland (Pisa et., 2015). We

52 seek to address this by considering the effect of neonicotinoid insecticides on population trends 53 of widespread UK butterflies. Neonicotinoid insecticides were introduced in the mid-1990s and 
54 are now widely used in arable farming both in the UK and globally. They are most commonly

55

56

57

58 used as a seed dressing on oilseed rape and cereals (Elbert et al., 2008), with the intention that the active ingredient is absorbed by the seedling and spreads systemically through the crop tissues. Studies into the effects of neonicotinoids on non-target species have mainly focussed on bees as concentrations ranging from $0.6-51$ parts per billion $(\mathrm{ppb})$ have been found in the nectar and pollen of treated crops (Cresswell, 2011, Blacquière et al., 2012, Pisa et al., 2015).

Neonicotinoids have been found to have a range of sublethal effects on honeybees and bumblebees, including impaired navigation and learning, reduced colony growth, impaired immunity and reduced queen production (Cresswell 2011, Henry et al., 2012, Whitehorn et al. 2012, Gill, Ramos-Rodriguez \& Raine, 2012, Di Prisco et al., 2013), but field experiments in which honeybee colonies have been exposed to plots of treated crops have not found significant impacts on colony health (Cutler et al. 2007, Pilling et al. 2013). It remains disputed whether neonicotinods are having significant impacts on bees in field situations (Godfray et al., 2014, Pisa et al., 2015). However, a recent field study has shown that treated rape seeds reduce the density of wild bees, the nesting of solitary bees and the growth of bumblebee colonies (Rundlöf et al., 2015).

Studies investigating the impacts of neonicotinoids on butterflies are completely lacking and urgently required (Pisa et al., 2015). Butterflies could be exposed to neonicotinoids via nectar from crops but also through contamination of non-crop plants and habitats. There are two routes by which seed-dressing neonicotinoids could contaminate farmland habitats such as field margin vegetation (Goulson 2014). Firstly, dust produced during drilling of dressed seeds can contain high concentrations of neonicotinoid, which drifts onto surrounding vegetation (Krupke et al., 2012; Girolami et al., 2013, Bonmatin et al., 2015). Secondly, neonicotinoids are 
77 water soluble and have a half-life in soil which can exceed 1,000 days (Baskaran et al., 1999, De

78 Cant \& Barrett, 2010, Goulson 2013). When used as a seed dressing, only 1.6 to $20 \%$ of the

active ingredient is taken up by the crop, the remainder leaching into soil water (Sur \& Storl, 2003). Recent studies show that concentrations of up to $9 \mathrm{ppb}$ can be found in field margin plants near seed-treated crops (Krupke et al., 2012, Stewart et al., 2014). If these levels are typical, then we might predict considerable direct mortality in herbivorous insects feeding on field margin vegetation, as concentrations of 5-10ppb are sufficient to control insect pests (Castle et al., 2005). The transportation of neonicotinoids by water courses means that butterflies feeding in other habitats could also be similarly affected.

Datasets investigating persistence of neonicotinoids within plants are very sparse.

However, vines treated in spring maintain levels of imidacloprid sufficient to control pests throughout the growing season (Byrne \& Toscano, 2006), and similarly levels of imidacloprid and thiamethoxam in citrus trees remained sufficient to suppress pests for 5 months (Castle et al., 2005). A single application of imidacloprid to maple trees protected them against insect pests for 4 years (Oliver et al., 2010). It is thus reasonable to propose that applications of neonicotinoids in adjacent crops could result in significant mortality of non-target invertebrates feeding in field margins for much of the spring and summer, and perhaps throughout the year. In the Netherlands declines in insectivorous birds have been found to be associated with the amount of imidacloprid in surface water (Hallmann et al., 2014). This study concludes that the impacts of neonicotinoids on non-target invertebrates are causing the declines in insectivorous birds. Here we extend previous models (Roy et al., 2001) of the UK population indices of 17 species of widespread butterflies that commonly breed and forage on farmland with the addition of the number of hectares within the UK treated with neonicotinoid pesticides as a new explanatory variable. 
Materials and Methods

102

103

\section{The Data}

104

We only selected widespread, resident species that routinely breed in any field or field margin habitats (Table 2), although all of the species also breed in other habitats. The indices for each species were derived from the UK Butterfly Monitoring Scheme (UKBMS) for the period 19842012 (Brereton et al., 2011). This dataset contains counts of butterflies from sites in a wide range of different habitats from across the UK. We included the full dataset for each species. The chosen period extends ten years before the introduction of neonicotinoid pesticides. Climatic data (total spring, total summer and total autumn rainfall, and mean spring and mean summer temperature) were obtained for the same period from the Met Office online database (Met Office 2014). We used the climate data that has previously been found to affect UK butterfly populations (Roy et al., 2001) and which has been proposed to have played a role in the 2000-

1142009 decline (Fox et al., 2011). Usage of neonicotinoids in the UK (acetamiprid, clothianidin, 115 imidacloprid, thiacloprid and thiamethoxam) was determined from Defra's online PUS STATS database (Defra 2014). A single total of the number of hectares treated with neonicotinoids was calculated for each year from 1994 (when they were first introduced) to 2012.

\section{Data analysis}

120 The data were analysed using a linear mixed effect random slope model using the R 3.1.2

121 package lme4 (R Project 2015). As the predictors were on very different scales all continuous 122 predictors were transformed to Z-scores prior to analysis. These were used to model the butterfly 
123 indices for the period 1985-2012 for all 17 species combined using the following explanatory

124 variables: mean spring temperature of the previous year, total spring rainfall in the previous year,

125 mean summer temperature of the previous year, total summer rainfall in the previous year, total

126 autumn rainfall in the previous year, mean spring temperature of the current year, total spring

127 rainfall in the current year, mean summer temperature of the current year, total summer rainfall

128 in the current year, year; population index for each species in the previous year; the number of

129 hectares treated with neonicotinoids in the UK for the previous year. The previous year's climate

130 data were included in the models as the adult population in a particular year may be influenced

131 by the climatic conditions experienced by the previous (parent) generation during the breeding

132 period and during the immature stages of their own lifecycle. Previous years' climate was found

133 to be important in earlier models (Roy et al., 2001; Brereton et al., 2011). We used spring

134 (March-May) and summer (June-August) weather as these are the main periods during which

135 larvae and adults are active and were found to be important in previous models of UK butterfly

136 population indices (Roy et al., 2001; Brereton et al., 2011). Autumn (September-November)

137 rainfall in the previous year was included as an additional climatic variable as this is the period

138 when neonicotinoids are generally used in the UK and rainfall is a likely mechanism by which

139 they could be transported into the wider environment. Neonicotinoid usage the previous year was

140 used for the same reason; most treated seeds are sown in autumn so it is the previous year's

141 application which is most likely to affect the current year's butterfly population indices. Species

142 was included as the only random effect. An interaction term between species and neonicotinoid

143 usage the previous year was also included. All predictor variables were tested for collinearity,

144 however none were considered to be correlated, with all Pearson correlation coefficients being

145 less than 0.3 . We used the dredge function of the MuMIn package (version 1.15.1) to identify the 
146 best models. The model coefficients and P-values were determined using the model.avg function

147 of the MuMIn package including all models whose cumulative weight summed up to a total of

148 0.95. The relative contribution of each model was weighted by their relative weight score. After

149 the minimum AIC mixed model was identified, random slope models including an interaction

150 term between species and predictors maintained in the minimum AIC model were generated. The

151 best model was again chosen using the dredge function. The ranef function was used to get the

152 best linear unbiased predictions for the random effects.

153 Neonicotinoid use started in the mid-90s but the rapid expansion in their use occurred in

154 the early part of the $21^{\text {st }}$ century (Defra 2014). Furthermore a recent study has suggested that

155 concentrations need to reach a threshold level before negative effects occur on non-target species

156 (Hallmann et al., 2014). Consequently the dataset was divided into two periods by year (1985-

1571998 and 1999-2012) to determine if there was a difference in the patterns of widespread

158 butterfly indices before and after the introduction of neonicotinoids. The separation point was

159 chosen as 1999 as 1998 was when neonicotinoid usage exceeded 100,000 hectares in the UK for

160 the first time (and never dropped back below this level) which also resulted in each group

161 containing the same number of years. A linear mixed effects model with year as a fixed effect

162 and species as a random was applied to each half of the dataset.

165 Results

166 In keeping with previous studies, our linear mixed effect random slope model revealed strong

167 positive associations between butterfly population index and both the previous year's index and 168 summer temperature (Table 1). However, a strong negative association with the previous year's 
169 usage of neonicotinoids was also revealed. The pattern of association with neonicotinoid usage

170 varied considerably between butterfly species (Figure 1) but is associated with declines in most

171 of the species (Table 2). The favoured habitat appears to be grassland for those species that

172 exhibit the strongest negative associations with neonicotinoid usage.

173 A linear mixed effects model with year as a fixed effect and species as a random effect

174 revealed that from 1985 to 1998 populations of these widespread butterflies actually exhibited a

175 significant increase (parameter estimate $=0.0073,95 \% \mathrm{CI}=0.0029 / 0.0116$ ). The same model

176 from 1999 to 2012 revealed a highly significant decline in butterfly populations (parameter

177 estimate $=-0.0145,95 \% \mathrm{CI}=-0.0187 /-0.0102)$. A linear mixed model including year and period

178 as fixed effects and species as a random effect and an interaction term between year and period

179 revealed that there was a significant difference in the slope of change in butterfly population

180 indices for these two periods (parameter estimate $=-0.0219,95 \%$ CI -0.0285 to -0.0147 )

\section{Discussion}

The analysis carried out in this study extended previous models of UK butterfly population indices (Roy et al., 2001; Warren et al., 2001; Brereton et al., 2011) to include the number of hectares of UK farmland treated with neonicotinoid insecticides. A strong negative correlation was revealed between the populations of a group of widespread butterfly species characteristic of UK farmland and neonicotinoid usage. These findings are correlative rather than causal and neonicotinoid usage may simply represent a proxy for other environmental factors associated with intensive agriculture. The parameter estimates from the model suggest that the strength of effect of neonicotinoids on butterfly population indices is equivalent to (albeit in the opposite direction from) the effect of the most important climatic variable, mean summer 
192 temperature. Neonicotinoid insecticide use has increased dramatically since it was first 193 introduced to the UK in 1994, while the populations of many of the butterfly species have 194 declined over the same period. Our model also included year as a fixed effect and revealed that, 195 although the analysis is purely correlative, the recent declines in butterfly populations are much 196 better explained by neonicotinoid usage than a linear decline over time. All 14 species which the 197 model identified as being most negatively affected by neonicotinoid usage exhibited 10-year 198 declines during the first decade of the $21^{\text {st }}$ century (Fox et al., 2011) when neonicotinoid usage 199 was increasing at its fastest rate (Table 2).

200 The explanatory strength of the neonicotinoid predictor in our models is all the more

201

202

203

204

205

206

207

208

209

210

211

212

213

214

notable, and unexpected, as our focal group of 17 widespread butterflies typically found in arable farmland landscapes all occur in a wide variety of other habitats. The UKBMS population data used in our study are compiled from sites representing many different habitats. Indeed, UKBMS sites usually comprise semi-natural habitats managed, at least in part, for biodiversity conservation. Thus the strong correlation between neonicotinoid usage and national butterfly trends is remarkable given that relatively few of the monitored butterfly populations would be from arable farmland.

Neonicotinoid usage, which represents a recent change to the environment, may explain the concurrent rapid decline in butterfly populations. Interestingly, a study of patterns of declines across the UK butterflies found that generalist butterflies are not declining in Scotland (Brereton et al., 2011) where neonicotinoid usage is much lower than it is in England (Figure 2; Defra 2014). In the Netherlands, where neonicotinoids are also widely used, major declines in populations of widespread butterflies have also been observed (van Dyck et al., 2009).

Furthermore, the spatial pattern of decline in insectivorous birds in the Netherlands correlates 
215 significantly with the presence of neonicotinoids in the environment (Hallmann et al., 2014). For

216 some species the observed effects may partly be due to adults being exposed while nectaring on

217 treated oilseed rape, the main flowering crop in the UK that is treated with neonicotinoids.

218 However, oilseed rape flowers in April-May, before the adults of other species seemingly

219 affected by neonicotinoids are on the wing. It seems probable then that any adverse effects of

220 neonicotinoids would be mediated primarily by contamination of larval food plants in the wider

221 environment such as field margins, although the declines in Pieris brassicae and P. rapae may

222 also be explained by the fact that they lay some of their eggs on the oilseed rape itself.

223 Habitat deterioration is the main candidate proposed to explain long-term declines in

224 distribution and abundance of butterflies in the UK during the $20^{\text {th }}$ century (Warren et al., 2001)

225 but there is no clear evidence that habitat has continued to deteriorate in the $21^{\text {st }}$ century to the

226 extent that it can explain the sudden crash in populations of widespread species after a period of

227 stability during the latter part of the $20^{\text {th }}$ century, so this hypothesis is difficult to test. Habitat

228 deterioration is difficult to quantify at large geographic scales and, therefore, has not been

229 included in previous models of butterfly trends (Roy et al., 2001; Warren et al., 2001; Brereton et

230 al., 2011). If habitat deterioration is the main cause of butterfly declines and agricultural

231 intensification is playing a key role in the loss of habitat, then neonicotinoid usage might be

232 acting as a proxy for agricultural intensification and therefore habitat deterioration in our models.

233 Thus, neonicotinoid usage could be responsible for driving butterfly declines or alternatively it

234 could provide the first useful quantifiable measure of agricultural intensification that strongly

235 correlates with butterfly population trends.

236 It should be noted that most UKBMS sites have not been characterised by habitat

237 although many comprise semi-natural habitats of relatively good quality compared to arable 
238 farmland and thus may not be directly exposed to neonicotinoids. However butterflies are mobile

239 organisms and declines at UKBMS sites could occur if they are surrounded by farmland

240 populations that act as population sinks (Dias, 1996). Furthermore, contamination of water by

241 neonicotinoids, which correlates strongly with the decline in insectivorous birds in the

242 Netherlands (Hallmann et al., 2014), provides the potential for rapid transport of neonicotinoids

243 from arable farmland to other surrounding habitats. This means that most other impacts of

244 agricultural intensification are likely to act on a relatively localised scale compared to

245 neonicotinoids. As most UKBMS sites are not in arable farmland this favours the hypothesis that

246 neonicotinoids are directly driving the declines in butterflies rather than acting as a proxy for

247 agricultural intensification.

248 Three areas of further research are required to elucidate the correlation we have found

249 between neonicotinoid use and butterfly populations. Experimental studies to determine the

250 toxicity of neonicotinoids to butterflies are required as a matter of utmost urgency. Improved

251 understanding of the levels of neonicotinoid contamination in field margin plants and surface

252 water are also needed to assess potential exposure. Finally, even if widespread butterflies are

253 being routinely exposed to harmful levels of neonicotinoids, further evidence is required to

254 determine if neonicotinoids are directly responsible for declines in national butterfly populations

255 or acting as a proxy for other factors associated with agricultural intensification. Further

256 development of the UKBMS models to incorporate land cover and habitat descriptors, as well as

257 additional climatic variables could add further insight into the factors playing a role in the recent

258 declines. If neonicotinoids are driving the decline in widespread butterflies in the UK, this begs

259 the questions as to what other non-target arthropods might be similarly affected and whether

260 neocotinoids are playing a role in the declines in insectivorous farmland birds in the UK. 
262 Acknowledgements

263 We are grateful to three reviewers of the manuscript for their constructive and helpful comments.

\section{References}

266

267

268

269

270

271

272

273

274

275

276

277

278

279

280

281

282

Baskaran S, Kookana RS, Naidu R. 1999. Degradation of bifenthrin, chlorpyrifos and imidacloprid in soil and bedding materials at termiticidal application rates. Pesticide Science 55: 1222-1228.

Batáry P, Dicks LV, Kleijn D, Sutherland WJ. 2015 The role of agri-environment schemes in conservation and environmental management. Conservation Biology 10.1111/cobi.12536.

Blacquière T, Smagghe G, van Gestel CAM, Mommaerts V. 2012. Neonicotinoids in bees: a review on concentrations, side-effects and risk assessment. Ecotoxicology 21: 973-992.

Bonmatin J-M, Giorio C, Girolami V, Goulson D, Kreutzweiser D, Krupke C, Liess M, Long E, Marzaro M, Mitchell E, Noome D, Simon-Delso N, Tapparo A. 2015. Environmental fate and exposure; neonicotinoids and fipronil. Environmental Science and Pollution Research 22: 35-67.

Brereton TM, Roy DB, Middlebrook I, Botham M, Warren M. 2011. The development of butterfly indicators in the United Kingdom and assessments in 2010. Journal of Insect Conservation 15: 139-151.

Brown LA, Ihara M, Buckingham SD, Matsuda K, Sattelle DB. 2006. Neonicotinoid insecticides display partial and super agonist actions on native insect nicotinic acetylcholine receptors. Journal of Neurochemistry 99: 608-615. 
283 Byrne FJ, Toscano NC. 2006. Uptake and persistence of imidacloprid in grapevines treated by 284 chemigation. Crop Protection 85: 831-834.

285 Castle SJ, Byrne FJ, Bi JL, Toscano NC. 2005. Spatial and temporal distribution of imidacloprid 286 and thiamethoxam in citrus and impact on Homalodisca coagulata populations. Pest Management Science 64: 75-84.

288

289

290

291

292

293

294

295

296

297

298

299

300

301

302

303

304

Cresswell JE, 2011. A meta-analysis of experiments testing the effects of a neonicotinoid insecticide (imidacloprid) on honey bees. Ecotoxicology 20: 149-157.

Cutler GC, Scott-dupree CD, 2007. Exposure to clothianidin seed-treated canola has no longterm impact on honey bees. Journal of Economic Entomology 100: 765-772.

De Cant J, M Barrett M. 2010. Environmental fate and ecological risk assessment for the registration of clothianidin for use as a seed treatment on mustard seed (oilseed and condiment) and cotton. United States Environmental Protection Agency report.

Defra. 2014. Pesticide usage statistics. Available at https://secure.fera.defra.gov.uk/pusstats/ (accessed June 2014).

Di Prisco G., Cavaliere V, Annoscia D, Varricchio P, Caprio E, Nazzi F, Gargiulo G, Pennachio F. 2013. Neonicotinoid clothianidin adversely affects insect immunity and promotes replication of a viral pathogen in honey bees. Proceedings of the National Academy of Sciences U. S. A. 110, 18466-18471.

Dias PC. (1996) Sources and sinks in population biology. Trends in Ecology and Evolution 12: 326-330.

Donald PF, Green RE, Heath MF. (2001) Agricultural intensification and the collapse of Europe's farmland bird populations. Proceedings of the Royal Society B 268: 25-29. 
305 Elbert A, Haas M, Springer B, Thielert W, Nauen R. 2008. Applied aspects of neonicotinoid uses

306 in crop protection. Pest Management Science 64: 1099-1105.

307 Fox R, Brereton TM, Asher J, Botham MS, Middlebrook I, Roy DB, Warren MS. 2011. The

308 State of the UK's Butterflies 2011. Butterfly Conservation and the Centre for Ecology \&

309 Hydrology, Wareham, Dorset. Available at https://butterfly-

$310 \quad$ conservation.org/files/soukb2011.pdf(accessed January 2015).

311 Gelman A, Hill J. 2007. Data analysis using regression and multilevel/hierarchical models.

312 Cambridge, UK: Cambridge University Press.

313 Gibbs KE, Mackey RL, Currie DJ. 2009. Human landuse, agriculture, pesticides and losses of

314 imperiled species. Diversity and Distributions 15: 242-253.

315 Gill RJ, Ramos-Rodriguez O, \& Raine NE. 2012. Combined pesticide exposure severely affects 316 individual- and colony-level traits in bees. Nature 491:105-108.

317 Girolami V, Marzaro M, Vivan L, Mazzon L, Giorio C, Marton D, Tapparo A. 2013. Aerial

318 powdering of bees inside mobile cages and the extent of neonicotinoid cloud surrounding 319 corn drillers. J. Applied Entomology 137: 35-44

320 Godfray HCJ, Blacquiere T, Field LM, Hails RS, Petrokofsky G, Potts SG, Raine NE, concerning neonicotinoid insecticides and insect pollinators. Proc. Roy. Soc. B DOI: 10.1098/rspb.2014.0558.

325 insecticides. Journal of Applied Ecology 50: 977-987.

326 Goulson, D. 2014. Pesticides linked to bird declines. Nature, 511: 295-296. 
327 Hallmann CA, Foppen RPB, van Turnhout CAM, de Kroon H, Jongejans E. 2014. Declines in

328 insectivorous birds are associated with high neonicotinoid concentrations. Nature 511: 341-343.

330

331

332

333

Henry M, Béguin M, Requier F, Rollin O, Odoux JF, Aupinel P, Aptel J, Tchamitchian S, Decourtye A. 2012. A common pesticide decreases foraging success and survival in honey bees. Science 336: 348-350.

JNCC 2015. Expenditure on UK and international biodiversity. Available at http://jncc.defra.gov.uk/page-4251 (accessed May 2015).

Kleijn D, Kohler F, Báldi A, Batáry P, Concepción ED, Clough Y, Díaz M, Gabriel D, Holzschuh A, Knop E, Kovács A, Marshall EJP, Tscharntke T, Verhulst J. 2009. On the relationship between farmland biodiversity and land-use intensity in Europe. Proceedings of the Royal Society B 276: 903-909.

Krupke CH, Hunt GJ, Eitzer BD, Andino G, Given K. 2012. Multiple routes of pesticide exposure for honey bees living near agricultural fields. PLOS ONE 7: e29268.

Met Office. 2014. UK climate datasets. Available at http://www.metoffice.gov.uk/climate/uk/datasets/(accessed June 2014).

Oliver JB, Fare DC, Youssef N, Scholl SS, Reding ME, Ranger CM, Moyseenko JJ, Halcomb MA. 2010. Evaluation of a single application of neonicotinoid and multi-application contact insecticides for flatheaded borer management in field grown red maple cultivars. Journal of Environmental Horticulture 28: 135-149.

Oliver TH, Hill JK, Thomas CD, Brereton T, Roy DB. 2009. Changes in habitat specificity of species at their climatic range boundaries. Ecology Letters 12: 1091-1102. 
349 Pilling E, Campbell P, Coulson M, Ruddle N, Tornier I, 2013. A four-year field program

350 investigating long-term effects of repeated exposure of honey bee colonies to flowering

351 crops treated with thiamethoxam. PLoS One 8: e77193-e77193.

352 Pisa LW, Amaral-Rogers V, Belzunces LP, Bonmatin JM, Downs CA, Goulson D, Kreutzweiser

353 DP, Krupke C, Liess M, McField M, Morrissey CA, Noome DA, Settele J, Simon-Delso

354 N, Stark JD, Van der Sluijs JP, Van Dyck H, Wiemers M. 2015. Effects of neonicotinoids

355 and fipronil on non-target invertebrates. Environmental Science and Pollution Research

$356 \quad 22: 68-102$.

357 R Project 2015. Available at http://www.r-project.org/ (accessed July 2015).

358 Roy DB, Rothery P, Moss D, Pollard E, Thomas JA. 2001. Butterfly numbers and weather:

359 predicting historical trends in abundance and the future effects of climate change. Journal 360 of Animal Ecology 70: 201-217.

361 Rundlöf M, Andersson GKS, Bommarco R, Fries I, Hederstrom V, Jonsson O, Klatt BK, 362 Pedersen TR, Yourstone J, Smith HG. 2015. Seed coating with a neonicotinoid insecticide 363 negatively affects wild bees. Nature 521: 77-80.

364 Schneider CW, Tautz J, Grunewald B, Fuchs S. 2012. RFID Tracking of Sublethal Effects of 365 Two Neonicotinoid Insecticides on the Foraging Behavior of Apis mellifera. PLoS ONE 7: 366 e30023.

367 Stewart SD, Lorenz GM, Catchot AL, Gore J, Cook D, Skinner J, Mueller TC, Johnson DR, 368 Zawislak J, Barber J. 2014. Potential Exposure of Pollinators to Neonicotinoid Insecticides 369 from the Use of Insecticide Seed Treatments in the Mid-Southern United States. Environtal 370 Science and Technology 48: 9762-9769. 
371 Sur R, Storl A. 2003. Uptake, translocation and metabolism of imidacloprid in plants. Bulletin of $372 \quad$ Insectology 56: 35-40.

373 van Dyck H, van Strien AJ, Maes D,. van Swaay CAM. 2009. Declines in common, widespread 374 butterflies in a landscape under intense human use. Conservation Biology 23: 957-965.

375 Warren MS, Hill JK, Thomas JA, Asher J, Fox R, Huntley B, Roy DB, Telfer MG, Jeffcoate S, 376 Harding P, Jeffcoate G, Willis SG, Greatorex-Davies JN, Moss D, Thomas CD. (2001). Rapid responses of British butterflies to opposing forces of climate and habitat change. Nature 414: 65-69.

WCBS 2014. Wider Countryside Butterfly Survey Annual Newsletter 2014 Season. Available at http://www.ukbms.org/Downloads/Wider_Countryside/Newsletter_WCBS_2014_FINAL.pd $f$ (accessed March 2015).

Whitehorn PR, O'Connor S, Wackers FL, Goulson D. 2012. Neonicotinoid pesticides reduces bumble bee colony growth and queen production. Science, 336: 351-352.

Fig.1. The fitted model values for the population indices for each species of butterfly plotted against the number of hectares applied with neonicotinoids the previous year from the linear mixed effect random slope model of butterfly indices, where species was included as a random effect and an interaction term was included between species and neonicotinoid usage the previous year. The index for each species is a log collated index scaled to have an average score of 2 across its entire time series (Brereton et al. 2011).

Fig. 2. The area in thousands of hectares treated with neonicotinoids in 2010 in different regions of England and Scotland. Data from Defra (2014). 
394 Table 1. The parameter estimates for the fixed effects included in the averaged linear mixed 395 effect random slope models of butterfly indices for the 17 species, where species was included as 396 a random effect and an interaction term was included between species and neonicotinoid usage 397 the previous year. All other variables were included as fixed effects. PY refers to previous year. 398 Table 2. The UKBMS ten year population trends for 2000-2009 (Fox et al., 2011) and parameter 399 estimates for each species from the averaged random slope linear mixed effect models for each 400 of the 17 butterfly species, where species was included as a random effect and an interaction 401 term was included between species and neonicotinoid usage the previous year. The habitat 402 preferences for each species are also provided from Oliver et al., 2009 for those species that were 403 included in that study $(\mathrm{G}=$ grassland, $\mathrm{HeMo}=$ hedgerow and mosaic habitats, $\mathrm{DW}=$ deciduous 404 woodland). The favoured habitat is given first and the number in parentheses denotes the 405 proportion of the UK population found in that habitat (Oliver et al., 2009). 
408

409

410

411 Table 1.

\begin{tabular}{|c|c|c|c|c|}
\hline Fixed Effect & Parameter & Standard error & T-value & P-value \\
& estimate & & & \\
\hline Intercept & 3.597 & 4.518 & 0.795 & 0.425 \\
\hline Population Index (PY) & 0.067 & 0.008 & 8.36 & $<0.001$ \\
\hline Neonicotinoid usage (PY) & -0.064 & 0.019 & 3.30 & $<0.001$ \\
\hline Summer temperature & 0.064 & 0.008 & 8.30 & $<0.001$ \\
\hline Spring rainfall (PY) & -0.026 & 0.007 & 3.58 & $<0.001$ \\
\hline Summer rainfall (PY) & 0.020 & 0.009 & 2.13 & 0.033 \\
\hline Spring temperature (PY) & -0.017 & 0.009 & -1.95 & 0.05 \\
\hline Spring temperature & 0.014 & 0.008 & 1.88 & 0.061 \\
\hline Spring rainfall & -0.010 & 0.008 & 1.31 & 0.191 \\
\hline Summer temperature (PY) & -0.009 & 0.010 & 0.83 & 0.404 \\
\hline Year & -0.002 & 0.003 & 0.70 & 0.485 \\
\hline & & & & \\
\hline
\end{tabular}

412

413 
414 Table 2.

\begin{tabular}{|c|c|c|c|}
\hline Species & $\begin{array}{c}\text { Effect of } \\
\text { neonicotinoid } \\
\text { usage on } \\
\text { population } \\
\text { index }\end{array}$ & $\begin{array}{c}10 \text { year } \\
\text { population } \\
\text { trend } \\
(2000- \\
2009)\end{array}$ & Habitat preference \\
\hline Wall Brown, Lasiommata megera & -0.135 & $-37 \%$ & G $(0.45)$ HeMo DW \\
\hline Small Skipper, Thymelicus sylvestris & -0.133 & $-62 \%$ & G $(0.53)$ HeMo DW \\
\hline Essex Skipper, Thymelicus lineola & -0.131 & $-67 \%$ & G $(0.53)$ HeMo DW- \\
\hline Small Tortoiseshell, Aglais urticae & -0.129 & $-64 \%$ & G $(0.49)$ HeMo DW \\
\hline Gatekeeper, Pyronia tithonus & -0.069 & $-23 \%$ & G $(0.45)$ HeMo DW \\
\hline Small White, Pieris rapae & -0.068 & $-26 \%$ & G $(0.40)$ HeMo DW \\
\hline Large Skipper, Ochlodes sylvanus & -0.066 & $-35 \%$ & G $(0.46)$ HeMo DW \\
\hline Large White, Pieris brassicae & -0.064 & $-34 \%$ & HeMo (0.38) G DW \\
\hline Common Blue, Polyommatus icarus & -0.061 & $-30 \%$ & G $(0.58)$ HeMo DW \\
\hline Peacock, Aglais io & -0.058 & $-24 \%$ & G $(0.38)$ HeMo DW \\
\hline Green-veined White, Pieris napi & -0.049 & $-9 \%$ & HeMo (0.40) G DW \\
\hline Small Copper, Lycaena phlaeas & -0.048 & $-24 \%$ & G $(0.54)$ HeMo DW \\
\hline Meadow Brown, Maniola jurtina & -0.037 & $-8 \%$ & G $(0.55)$ HeMo DW \\
\hline Marbled White, Melanargia galathea & -0.034 & $-21 \%$ & G $(0.60)$ HeMo DW \\
\hline Orange-tip, Anthocharis cardamines & -0.022 & $-8 \%$ & HeMo (0.39) G DW \\
\hline Comma, Polygonia c-album & 0.007 & $+34 \%$ & HeMo (0.42) DW G \\
\hline Ringlet, Aphantopus hyperantus & 0.009 & $+25 \%$ & G (0.42) HeMo DW \\
\hline
\end{tabular}




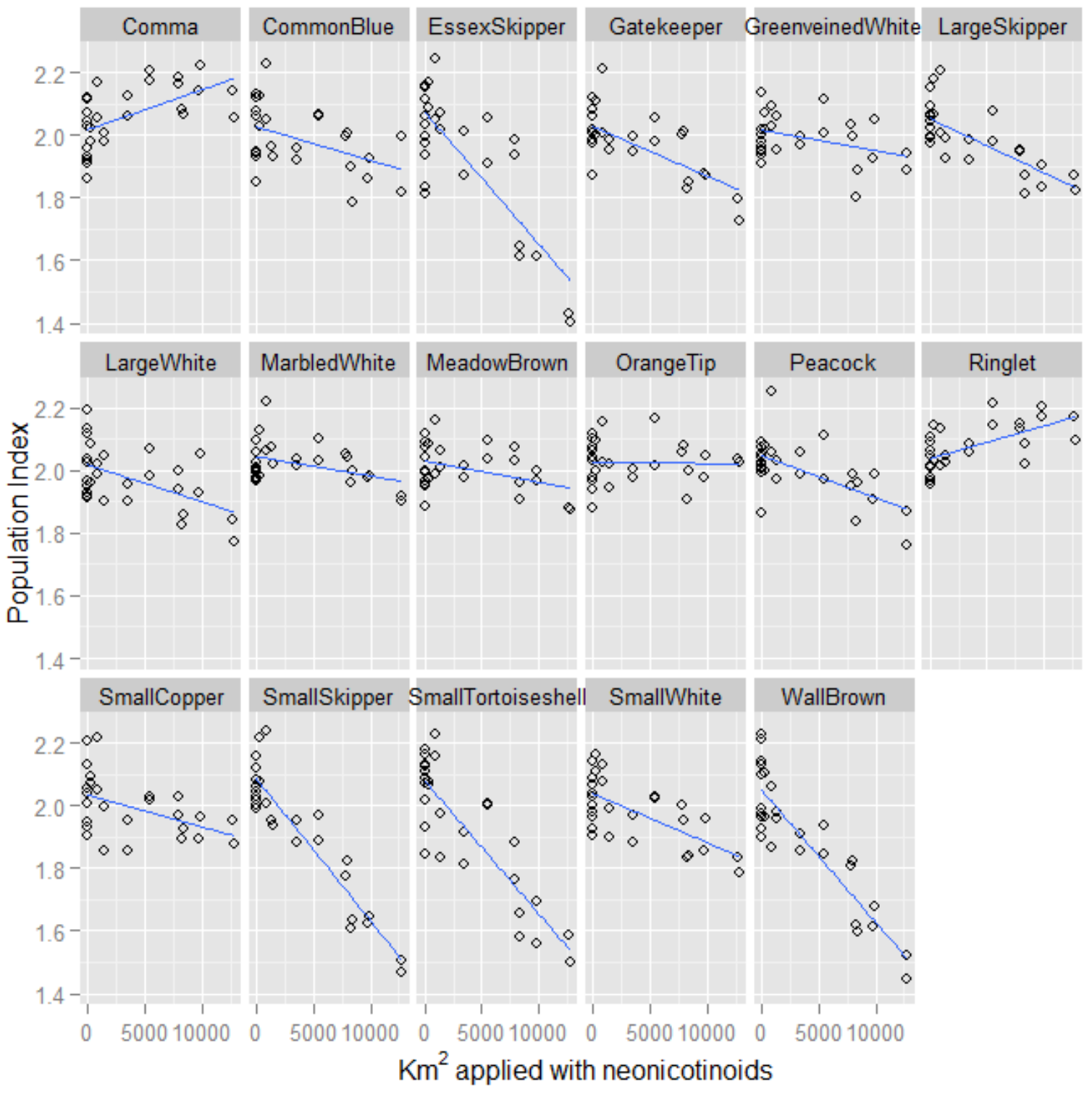

415

$\mathrm{Km}^{2}$ applied with neonicotinoids

416 Fig. 1.

417 


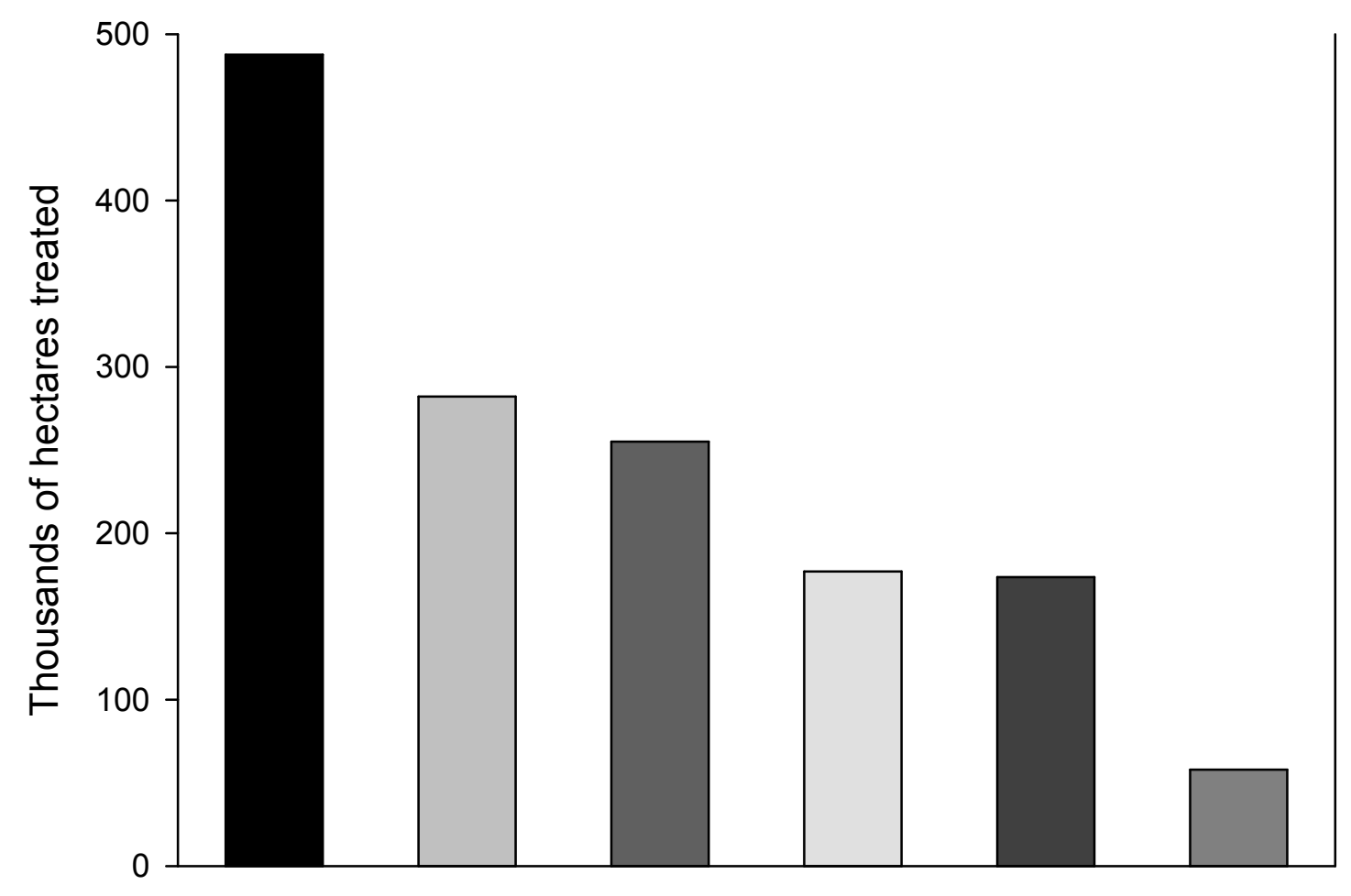

Fig. 2.

421 


\section{Table $\mathbf{1}$ (on next page)}

Model of the impact of neonicotinoids on butterfly population indices

The parameter estimates for the fixed effects included in the averaged linear mixed effect random slope models of butterfly indices for the 17 species, where species was included as a random effect and an interaction term was included between species and neonicotinoid usage the previous year. All other variables were included as fixed effects. PY refers to previous year. 
1

\begin{tabular}{|c|c|c|c|c|}
\hline Fixed Effect & Parameter & Standard error & T-value & P-value \\
& estimate & & & \\
\hline Intercept & 3.597 & 4.518 & 0.795 & 0.425 \\
\hline Population Index (PY) & 0.067 & 0.008 & 8.36 & $<0.001$ \\
\hline Neonicotinoid usage (PY) & -0.064 & 0.019 & 3.30 & $<0.001$ \\
\hline Summer temperature & 0.064 & 0.008 & 8.30 & $<0.001$ \\
\hline Spring rainfall (PY) & -0.026 & 0.007 & 3.58 & $<0.001$ \\
\hline Summer rainfall (PY) & 0.020 & 0.009 & 2.13 & 0.033 \\
\hline Spring temperature (PY) & -0.017 & 0.009 & -1.95 & 0.05 \\
\hline Spring temperature & 0.014 & 0.008 & 1.88 & 0.061 \\
\hline Spring rainfall & -0.010 & 0.008 & 1.31 & 0.191 \\
\hline Summer temperature (PY) & -0.009 & 0.010 & 0.83 & 0.404 \\
\hline & -0.002 & 0.003 & 0.70 & 0.485 \\
\hline & & & & \\
\hline
\end{tabular}

2 


\section{Table 2 (on next page)}

\section{Ten year trends and parameter estimates for the 17 butterfly species}

The UKBMS ten year population trends for 2000-2009 (Fox et al., 2011) and parameter estimates for each species from the averaged random slope linear mixed effect models for each of the 17 butterfly species, where species was included as a random effect and an interaction term was included between species and neonicotinoid usage the previous year. The habitat preferences for each species are also provided from Oliver et al., 2009 for those species that were included in that study ( $G=$ grassland, HeMo = hedgerow and mosaic habitats, DW = deciduous woodland). The favoured habitat is given first and the number in parentheses denotes the proportion of the UK population found in that habitat (Oliver et al., 2009). 
1

\begin{tabular}{|c|c|c|c|}
\hline Species & $\begin{array}{c}\text { Effect of } \\
\text { neonicotinoid } \\
\text { usage on } \\
\text { population } \\
\text { index } \\
\end{array}$ & $\begin{array}{l}10 \text { year } \\
\text { population } \\
\text { trend } \\
(2000- \\
2009) \\
\end{array}$ & Habitat preference \\
\hline Wall Brown, Lasiommata megera & -0.135 & $-37 \%$ & G (0.45) HeMo DW \\
\hline Small Skipper, Thymelicus sylvestris & -0.133 & $-62 \%$ & G (0.53) HeMo DW \\
\hline Essex Skipper, Thymelicus lineola & -0.131 & $-67 \%$ & G (0.53) HeMo DW- \\
\hline Small Tortoiseshell, Aglais urticae & -0.129 & $-64 \%$ & G (0.49) HeMo DW \\
\hline Gatekeeper, Pyronia tithonus & -0.069 & $-23 \%$ & G (0.45) HeMo DW \\
\hline Small White, Pieris rapae & -0.068 & $-26 \%$ & G (0.40) HeMo DW \\
\hline Large Skipper, Ochlodes sylvanus & -0.066 & $-35 \%$ & G (0.46) HeMo DW \\
\hline Large White, Pieris brassicae & -0.064 & $-34 \%$ & HeMo (0.38) G DW \\
\hline Common Blue, Polyommatus icarus & -0.061 & $-30 \%$ & G (0.58) HeMo DW \\
\hline Peacock, Aglais io & -0.058 & $-24 \%$ & G (0.38) HeMo DW \\
\hline Green-veined White, Pieris napi & -0.049 & $-9 \%$ & HeMo (0.40) G DW \\
\hline Small Copper, Lycaena phlaeas & -0.048 & $-24 \%$ & G (0.54) HeMo DW \\
\hline Meadow Brown, Maniola jurtina & -0.037 & $-8 \%$ & G (0.55) HeMo DW \\
\hline Marbled White, Melanargia galathea & -0.034 & $-21 \%$ & G (0.60) HeMo DW \\
\hline Orange-tip, Anthocharis cardamines & -0.022 & $-8 \%$ & HeMo (0.39) G DW \\
\hline Comma, Polygonia c-album & 0.007 & $+34 \%$ & HeMo (0.42) DW G \\
\hline
\end{tabular}

2 


\section{Figure 1 (on next page)}

Fitted values for each butterfly species plotted against neonicotinoid usage

The fitted model values for the population indices for each species of butterfly plotted against the number of hectares applied with neonicotinoids the previous year from the linear mixed effect random slope model of butterfly indices, where species was included as a random effect and an interaction term was included between species and neonicotinoid usage the previous year. The index for each species is a log collated index scaled to have an average score of 2 across its entire time series (Brereton et al. 2011). 


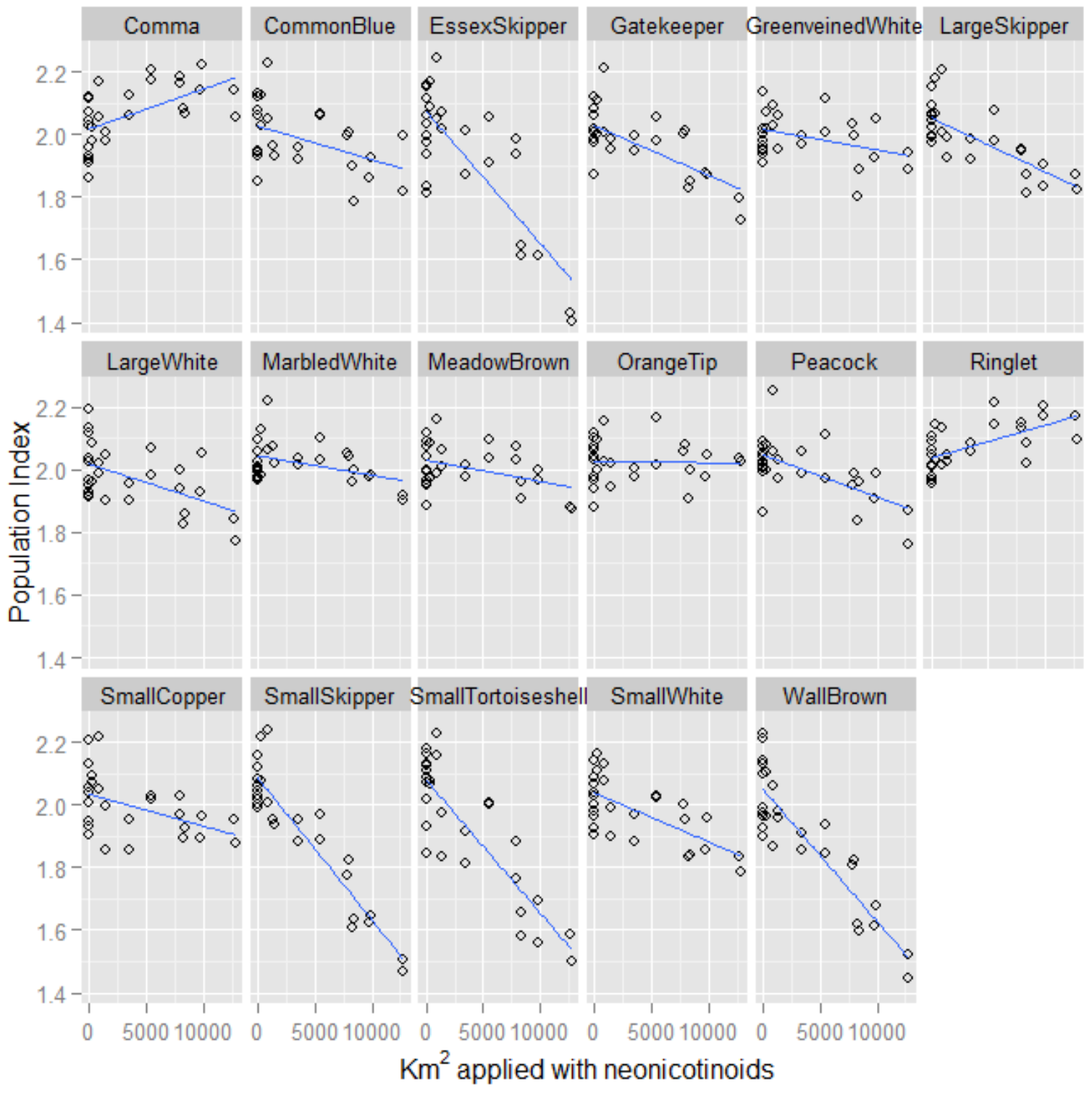




\section{Figure 2 (on next page)}

\section{Neonicotinoid usage by region}

The area in thousands of hectares treated with neonicotinoids in 2010 in different regions of England and Scotland. Data from Defra (2014). 


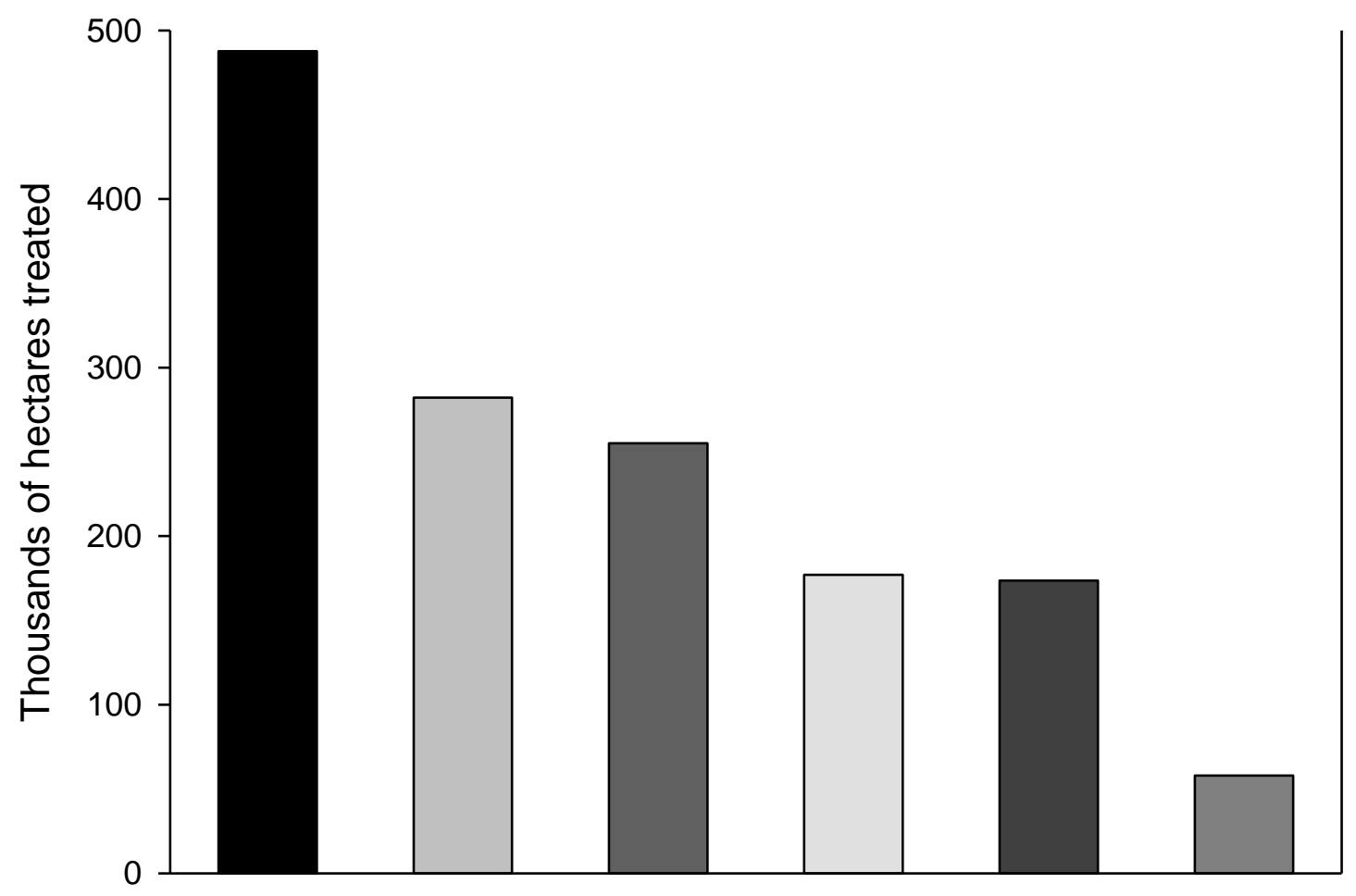

\begin{tabular}{|l|}
\hline$\square$ East \\
$\square$ Southwest \\
Southeast \\
$\square$ Midlands \& West \\
North \\
Scotland \\
\hline
\end{tabular}

